maxilla that might predispose to retropalatal upper airway narrowing. Since facial structure is at least partly inherited, this may provide the familial link in the sudden infant death syndrome, although larger studies are required to confirm these findings. These results also provide a further link between the sudden infant death and obstructive sleep apnoea/hypopnoea syndromes, as the facial changes are similar in both conditions.

Our study indicates that a retrognathic facial structure should be considered as an additional risk factor for the sudden infant death syndrome, and the suggested mechanism for upper airway narrowing could also contribute to the posture dependence of the syndrome and to the association with upper respiratory tract infections, which predispose to obstructive apnoeas by increasing nasal resistance. We suggest there is a need to assess whether prevention of obstructive apnoeas, such as by continuous positive airway pressure, prevents the sudden infant death syndrome in high risk infants.
Contributors: KR measured all the radiographs and participated in the design of the study and in writing the article. NJD participated in the design of the study, data analysis, and in writing the article. AW took the radiographs and participated in writing the article. JWK performed all the necropsies and participated in the design of the study and in writing the article. NJD is guarantor for the article.

Funding: KR was funded by ResMed during this study. Conflict of interest: None.

1 Kahn AA, Groswasser J, Rebuffat E, Sottiaux M, Blum D, Foerster M, et al. Sleep and cardiorespiratory characteristics of infant victims of sudden death: a case control study. Sleep 1992;15:287-92.

2 Skatvedt O, Grogaard J. Infant sleeping position and inspiratory pressures in the upper airways and oesophagus. Arch Dis Child 1994;71:138-40.

3 Mathur R, Douglas NJ. Relationship between sudden infant death syndrome and adult sleep apnoea/hypopnoea syndrome. Lancet 1994:334:819-20

4 Tishler PV, Redline S, Ferrette V, Hans MG, Altose MD. The association of sudden unexpected infant death with obstructive sleep apnea. Am J Respir Crit Care Med 1996;153:1857-63.

5 Mathur R, Douglas NJ. Family studies in patients with the sleep apnoea hypopnoea syndrome. Ann Intern Med 1995;122:174-8.

(Accepted 27 February 1998)

\title{
Disease activity and risk of lymphoma in patients with rheumatoid arthritis: nested case-control study
}

\author{
Eva Baecklund, Anders Ekbom, Pär Sparén, Nils Feltelius, Lars Klareskog
}

Department of

Medicine,

University Hospital,

S-751 85 Uppsala,

Sweden

Eva Baecklund,

rheumatologist

Nils Feltelius,

associate professor

Department of

Medical

Epidemiology,

Karolinska Institute,

Box 281, S-171 11

Stockholm, Sweden

Anders Ekbom,

associate professor

Pär Sparén,

statistician

Department of

Medicine,

Karolinska Hospital,

S-171 76

Stockholm, Sweden

Lars Klareskog,

professor

Correspondence to:

Dr Baecklund

Eva.Baecklund@

swipnet.se

BMJ 1998;317:180-1
Inflammatory diseases such as rheumatoid arthritis and their treatment may have a pathogenic relation with cancer. The possible relation also has practical implications for the care and control of rheumatic patients.

Patients with rheumatoid arthritis have been shown to have an increased risk of developing lymphomas. ${ }^{12}$ The underlying mechanisms for this association are unclear. We performed a study to assess to what extent disease activity, various secondary manifestations of rheumatic disease, and drug treatment were independent risk factors for the development of lymphoma in patients with rheumatoid arthritis.

\section{Subjects, methods, and results}

We performed a nested case-control study using a previously described population based cohort of all patients admitted to hospital with rheumatoid arthritis during 1965-83 in Uppsala health care region, Sweden. ${ }^{3}$ We identified 42 cases of lymphoma in the 11683 patients with rheumatoid arthritis through record linkages with the Swedish cancer registry. Cases were individually matched to three controls from the same rheumatoid arthritis cohort. All medical records were reviewed and data, including disease manifestations and treatment from the first symptoms compatible with rheumatoid arthritis until the date of the diagnosis of the lymphoma in the case, were abstracted for cases and controls. All cases and controls were evaluated to assess if the 1987 American College of Rheumatology criteria for rheumatoid arthritis were met, and patients not having rheumatoid arthritis were excluded. The risk of lymphoma was measured as unadjusted and adjusted odds ratios. The study finally consisted of 41 cases and 113 controls.

The table gives exposures linked to an increased risk of lymphoma together with the unadjusted odds ratios. High inflammatory activity was the most prominent risk factor for development of lymphoma, with an odds ratio of 25.8 compared with low inflammatory activity. Inflammatory activity was estimated by a score comprising the whole period of rheumatoid arthritis disease and was based on available data on erythrocyte sedimentation rates, number of swollen and tender joints, and the treating physician's global assessment of disease activity. Other exposures associated with disease severity also entailed an increased odds ratio for lymphoma, such as functional class IV of Steinbrocker (odds ratio 12.9), widespread joint involvement (odds ratio 9.3), and certain extra-articular symptoms.

Few patients were treated with immunosuppressive drugs, reflecting the standard treatment during the study period. Non-steroidal anti-inflammatory drugs, aspirin, and corticosteroids were in common use, but only a few patients were treated with antimalarials, parenteral gold, D-penicillamine, podophyllotoxin, or sulphasalazine.

We found no association between any specific drug and increased risk of lymphoma. Once drug treatment was adjusted for there was a strong independent 
association between inflammatory activity and lymphoma.

\section{Comment}

This study shows a strong association between disease activity in patients with rheumatoid arthritis and risk of developing lymphoma. It strengthens the concept that disease related immune alterations in rheumatoid arthritis also increase the risk of lymphoma, regardless of drug treatment. ${ }^{4}$ The risk linked to the disease seems larger than risks linked to immunosuppressive treatment seen in other studies. ${ }^{5}$ Thus our findings provide additional arguments for use of potent immunosuppressive treatment to reduce disease activity, not only to prevent joint damage but possibly also to protect against lymphoma.

Doctors need to be aware of the risk of lymphoma in certain groups of patients with rheumatoid arthritis. In addition, clinical investigators into new drugs for rheumatoid arthritis should take into account the "background" risk of lymphoma in patients with highly active rheumatoid arthritis, who are usually preferred in these trials.

Contributors: EB collected and analysed data, participated in interpreting the data, and wrote the paper. $\mathrm{AE}$ initiated and designed the study, supervised data collection, contributed to interpreting the data and writing the paper, and is the study guarantor. PS was responsible for the statistical parts of the study, and helped with analysis, data interpretation, and writing the paper. NF helped with the study design, data interpretation, and writing the paper. LK discussed core ideas and helped in interpreting the data and writing the paper.
Disease characteristics associated with increased unadjusted odds ratio for lymphoma

\begin{tabular}{|c|c|c|c|}
\hline Exposure & $\begin{array}{c}\text { No }(\%) \text { of } \\
\text { cases }(n=41)\end{array}$ & $\begin{array}{c}\text { No }(\%) \text { of } \\
\text { controls }(n=113)\end{array}$ & Odds ratio $(95 \% \mathrm{CI})$ \\
\hline \multicolumn{4}{|l|}{ Inflammatory activity } \\
\hline Low & $2(5)$ & $31(27)$ & 1.0 \\
\hline Medium & $16(39)$ & $65(58)$ & $5.4(0.7$ to 42.0$)$ \\
\hline High & $23(56)$ & $17(15)$ & 25.8 (3.1 to 213.0$)$ \\
\hline \multicolumn{4}{|l|}{ Functional class of Steinbrocker } \\
\hline I & $2(5)$ & $18(16)$ & 1.0 \\
\hline II & $9(22)$ & $56(50)$ & $1.1(0.2$ to 5.9$)$ \\
\hline III & $13(32)$ & $26(23)$ & $4.7(0.8$ to 26.2$)$ \\
\hline IV & $17(41)$ & $13(11)$ & 12.9 (2.1 to 76.8$)$ \\
\hline \multicolumn{4}{|l|}{ Joints affected } \\
\hline Small & $3(7)$ & $36(32)$ & 1.0 \\
\hline Small and large & $38(93)$ & $77(68)$ & $9.3(2.1$ to 41.5$)$ \\
\hline \multicolumn{4}{|l|}{ Other characteristics } \\
\hline Complications/extra-articular manifestations & $14(34)$ & $23(20)$ & $2.1(0.9$ to 4.9$)$ \\
\hline Atlantoaxial subluxation & $4(10)$ & $1(1)$ & $11.2(1.2$ to 100.0$)$ \\
\hline Amyloidosis & $3(7)$ & $1(1)$ & $9.0(0.9$ to 86.5$)$ \\
\hline Nodules & $9(22)$ & $7(6)$ & 7.6 (1.5 to 37.1$)$ \\
\hline
\end{tabular}

Funding: None

Conflict of interest: None.

1 Prior P, Symmons DPM, Hawkins CF, Scott DL, Brown R. Cancer morbidity in rheumatoid arthritis. Ann Rheum Dis 1984;43:128-31.

2 Myllykangas-Luosujärvi R, Aho K, Isomäki H. Mortality from cancer in patients with rheumatoid arthritis. Scand J Rheumatol 1995;24:76-8.

3 Gridley G, McLaughlin JK, Ekbom A, Klareskog L, Adami HO, Hacker $\mathrm{DG}$, et al. Incidence of cancer among patients with rheumatoid arthritis. $J$ Natl Cancer Inst 1993;85:307-11.

4 Symmons DPM. Neoplasms of the immune system in rheumatoid arthritis. Am J Med 1985; 78:22-8.

5 Silman AJ, Petrie J, Hazleman B, Evans SJW. Lymphoproliferative cancer and other malignancy in patients with rheumatoid arthritis treated with azathioprine: a 20 year follow up study. Ann Rheum Dis 1988;47:988-92. (Accepted 27 January 1998)

\section{Drug points}

\section{Eosinophilic pneumonia induced by dapsone}

D Jaffuel, B Lebel, D Hillaire-Buys, J Pene, P Godard, F-B Michel, J-P Blayac, J Bousquet, P Demoly, Maladies Respiratoires and Centre Regional de Pharmacovigilance, Centre Hospitalier Universitaire de Montpellier, 34295 Montpellier Cedex 5, France

Pulmonary eosinophilia can be caused by numerous drugs and may be life threatening. To our knowledge, only one case of eosinophilic pneumonia associated with dapsone has been reported. ${ }^{1}$ We report a case of pulmonary eosinophilia induced by dapsone and confirmed by unintentional rechallenge with the drug.

A 60 year old woman with chronic urticaria was treated with dapsone $(100 \mathrm{mg} /$ day) in November 1994 because conventional treatment $\left(\mathrm{H}_{1}\right.$ receptor antagonists and corticosteroids) was insufficient. Two weeks later she presented at a local hospital with dyspnoea, wheezing, productive cough, and a fever of $38.5^{\circ} \mathrm{C}$. Physical examination showed crackles. Laboratory tests showed a rise in the erythrocyte sedimentation rate to $86 \mathrm{~mm}$ in the first hour, a leucocyte count of $11.3 \times 10^{9} / 1(9.4 \%$ eosinophils $)$, and a haemoglobin concentration of $70 \mathrm{~g} / \mathrm{l}$. A chest radiograph showed bilateral interstitial infiltrates. Dapsone treatment was withdrawn because of the anaemia, and treatment with ampicillin and erythromycin was started. This led to a rapid reduction in lung symptoms and the disappearance of the radiographic infiltrates. Atypical pneumonia was diagnosed.

In February 1995 dapsone was prescribed again for worsening urticaria. A few hours after starting treatment she had a further episode of dyspnoea, cough, and fever. Her family doctor stopped dapsone treatment and referred her to our hospital 48 hours later. On admission, only cough and bilateral crackles persisted. Leucocyte count, haemoglobin concentration, blood gas concentrations, a chest radiograph, and the results of lung function tests were normal. Bronchoalveolar lavage fluid contained 136800 cells/ml (21\% eosinophils) but no infectious agents. Eight months after dapsone treatment was stopped a physical examination and repeat tests gave normal results. We did not find any blood histamine release or lymphocyte proliferation in the presence of dapsone.

This case suggests that dapsone should be added to the list of drugs that induce eosinophilic pneumonia. ${ }^{1}$ Four cases of eosinophilic pneumonia have been reported for the combination of pyrimethamine with dapsone. ${ }^{2}$ Pyrimethamine was incriminated in all cases without any formal proof. ${ }^{4}$ Our data show that dapsone may be implicated in some cases of eosinophilic pneumonia induced by the combination of pyrimethamine with dapsone.

1 Janier M, Guillevin L, Badillet G. Pulmonary eosinophilia associated with dapsone. Lancet 1994;343:860-1.

2 Davidson AC, Bateman C, Shovlin C, Marrinan M, Burton GH, Cameron IR. Pulmonary toxicity of malaria prophylaxis. BMJ 1988;297:1240-1.

3 Graham WR Jr. Adverse effects of dapsone. Int J Dermatol 1975;14:494 500 .

4 Pang JA. Non-cardiogenic pulmonary oedema associated with pyrimethamine. Respir Med 1989;83:247-8. 